\title{
The Mult/Cath study: creating an evidence base
}

I n healthcare we hear much about evidencebased practice and patient choice. But evidence and choice are lacking in one key area of urological nursing: intermittent catheterisation (IC) and, in particular, the selection of catheters for IC.

\section{Evidence about single-use or re-use of catheters in IC}

In the UK, people who use IC to empty their bladder are supplied with and taught to use single-use urinary catheters. Some are packaged with their own reservoir of lubricant and some have lubricant coatings that are activated by water. Before the adoption of these single-use products a couple of decades ago, many used simple PVC catheters. These were washed after use, stored in clean containers and re-used with tubes or sachets of lubricant (Buckley et al, 2015).

There is a widespread perception among urology nurses and other clinicians that the adoption of single-use catheters came about because they are safer in terms of prevention of infection or insertion-related trauma. In fact there is little evidence to suggest that this is the case. Two up-to-date systematic reviews of existing evidence have concluded that there is little reason to recommend any method of IC is better or worse in terms of urinary tract infection (UTI). In addition, there is insufficient data to show differences between coated and uncoated catheters in terms of urethral trauma or haematuria (Bermingham et al, 2013; Prieto et al, 2014).

\section{Why use single-use catheters?}

The switch to single-use catheters came about largely because of regulatory changes. Previously the simple reusable PVC catheters were labelled 'single-patient use', whereas coated catheters were labelled 'single-use'. New regulations introduced by the Medicines and Healthcare products Regulatory Agency (MHRA) in 2006 stated that the manufacturers of any medical products intended for re-use must provide tested cleaning instructions. (MHRA, 2013) For catheter manufacturers it was easier to avoid this by simply relabelling the simple PVC catheters 'single-use'. Although the products did not change, the result was that no reusable catheters were available on UK markets and patient choice was reduced.
The dependence of the NHS on single-use IC catheters is not the worldwide norm. In many places the re-use of catheters remains commonplace and accepted. Recent studies in developed countries such as the USA, Canada and Australia have found that nearly half of those performing IC regularly reuse catheters (Woodbury et al, 2008; Bolinger and Engberg, 2013; Leek et al, 2013). In developing countries, where access to and affordability of single-use products is problematic, re-use is the norm.

\section{Patient choice and flexibility}

Qualitative research from around the world suggests that some patients prefer single-use catheters; they find them easy and comfortable to use, and convenient. Others consider these catheters, which are usually pre-lubricated, to be difficult to handle and find the daily need to carry and dispose of several catheters difficult and wasteful. Reusable catheters mean always having a catheter available and having to throw away fewer catheters. Users also reported the importance of flexibility - the ability to choose products that fit in with their lives rather than being dependent on only one product (Wilde et al, 2011).

'Mixed use' of both single-use and reusable catheters may provide patients with the opportunity to benefit from the advantages of both types. IC users in the UK consider that re-use of catheters at least some of the time is an appealing option if it is proved to be safe (Sartain et al, 2015).

Generating much-needed evidence for best practice in IC

The MultICath research programme began in 2013 with the aims of:

- Producing robust evidence as to whether mixed use of catheters is safe, acceptable and cost effective

- Scoping the potential for increasing choice for patients

- Identifying areas for innovation in intermittent catheters.

The programme is funded by the National Institute for Health Research (NIHR) and conducted by a collaboration of five UK universities in partnership with NHS trusts and with the support of professional and patient organisations.
The first 2 years of the programme have focused on three main areas:

- Cleaning methods - three user panels have assisted researchers in developing and testing cleaning methods for plain catheters and identifying which are acceptable. Catheters have been sent to microbiology laboratories to assess the efficacy of the cleaning method.

- Outcome measurement-patient views have been collected about reuse and single use of catheters, about the symptoms that are common when they have UTIs, and about what they do to avoid them. A new quality-of-life (QoL) measurement tool (Pinder et al, 2012) is also being tested with users. The findings from these interviews and observations will inform and refine the tools used to measure UTI and QoL during the trial.

- Stakeholder perspectives: current nursing practice in teaching IC, along with the views of nurses and other stakeholders, are being determined through electronic survey and interviews. Manufacturers are also being consulted about their views on re-use, the potential for market innovations in reusable products.

The results of the first 2-year phase of the programme have been promising and the second phase, a 3-year randomised controlled trial, will start in the coming months. In the trial, patients will be randomised to use either singleuse catheters only or a 'mixed-use' package comprising use of both single-use and reusable catheters. Participants will receive a home visit and the mixed-use group will get a cleaning kit and instructions in booklet and DVD form. Monthly phone calls will be used to maintain contact with participants and ensure return of data-in particular when UTIs are experienced.

The trial is designed to establish whether mixed-use is at least as safe as single-use only, and is acceptable to patients. The primary outcome will be incidence of clinical UTI during a 12-month follow-up period. Other outcomes will include episodes of haematuria and bleeding, pain/discomfort, and QoL and preference. The trial, run by the Clinical Trials Unit at Newcastle University, will take place across England and Scotland and the findings will inform future guidance from the National Institute for Health and Care Excellence and MHRA. 


\section{How can urology nurse specialists help?}

Urology nurse specialists are an important point of contact for all members of the multidisciplinary team and patients, and therefore have key a role in facilitating clinical research by updating colleagues about studies and enabling patients to consider taking part in studies relevant to them.

Some staff and their patients will have very strong views about the potential incorporation of reusable catheters into practice as part of mixed use of single and reusable catheters. Given the lack of evidence in this area, it is important that urology nurse specialists keep an open mind about re-use of catheters and encourage their patients to consider taking part. For many urology nurse specialists, single use has been the norm for their entire careers and many patients are unaware that the re-use of catheters once existed, and it is important to be sensitive to this when talking to colleagues and patients about the trial.

The MultICath trial will be most effective if it has the support and involvement of urology nurse specialists. We will be asking urologists and urology nurse specialists across the UK to promote the study among their patients. BJN
If you would like further information please visit www.soton.ac.uk/multicath or contact Margaret Macaulay, project manager,multicath@soton.ac.uk.

Acknowledgements: The authors wish to acknowledge the contribution of the MultICath trial team to this work.

National Institute for Health Research (NIHR) under its Programme Grants for Applied Research (PGfAR) Programme (Grant Reference Number RP-PG-0610-10078). The views expressed are those of the authors and not necessarily those of the NHS, the NIHR or the Department of Health.

Bermingham SL, Hodgkinson S, Wright S, Hayter E, Spinks J, Pellowe C (2013) Intermittent self catheterisation with hydrophilic, gel reservoir, and non-coated catheters: a systematic review and cost effectiveness analysis. BMJ 346: e 8639

Bolinger R, Engberg S (2013) Barriers, complications, adherence, and self-reported quality of life for people using clean intermittent catheterization. J Wound Ostomy Continence Nurs 40(1): 83-9. doi: 10.1097/ WON.0b013e3182750117

Buckley B, Fader M, Macauley M (2015) Giving intermittent catheter users more choice. Br J Gen Pract 65(637): 419. doi: 10.3399/bjgp15X686209

Leek H, Stephenson Z, Reus A, Karantanis E, Moore KH (2013) Clean intermittent self-catheterisation: a randomised controlled crossover trial of single-use versus multiple re-use of non-coated catheters: is cystitis rate altered? Neurourol Urodyn 32: 759-60

Medicines and Healthcare products Regulatory Agency (2013) Single-use medical devices: implications and consequences of reuse. http://tinyurl.com/nvq4o $7 \mathrm{~m}$. (accessed 25 September 2015)

Pinder B, Lloyd AJ, Elwick H, Denys P, Marley J, BonniaudV (2012) Development and psychometric validation of the intermittent self-catheterization questionnaire. Clin Ther 34(12): 2302-13. doi: 10.1016/j.clinthera.2012.10.006

Prieto J, Murphy CL, Moore KN, Fader M (2014) Intermittent catheterisation for long-term bladder management. Cochrane Database of Systematic Reviews. 10.1002/14651858.CD006008.pub3

Sartain S, Avery M, Prieto J, Macaulay M, Fader M (2015) Determining the advantages and disadvantages unique to single-catheter and multi-catheter use for clean intermittent catheterisation. [Accepted abstract at United Kingdom Continence Society 22nd Annual Scientific Meeting Aberdeen, 25-27 March 2015] http://tinyurl. com/oz7svxt (accessed 28 September 2015)

Wilde MH, Brasch J, ZhangY (2011) A qualitative descriptive study of self-management issues in people with long-term intermittent urinary catheters. J Adv Nurs 67(6): 1254-63. doi: 10.1111/j.1365-2648.2010.05583.x

Woodbury MG, Hayes KC, Askes HK (2008) Intermittent catheterization practices following spinal cord injury: a national survey. Can J Urol 15(3): 4065-71

\section{Brian Buckley}

Independent Health Service Researcher

\section{Matthew Archer}

Urology Nurse Specialist, University Hospital Southampton NHS Foundation Trust

\section{Margaret Macaulay}

Research Nurse/Project Co-ordinator, University College London

\section{Mandy Fader}

Professor of Continence Technology, University of Southampton
Quarterly supplement covering all aspects of tissue viability in nursing from prevention with compression techniques to wound care and management

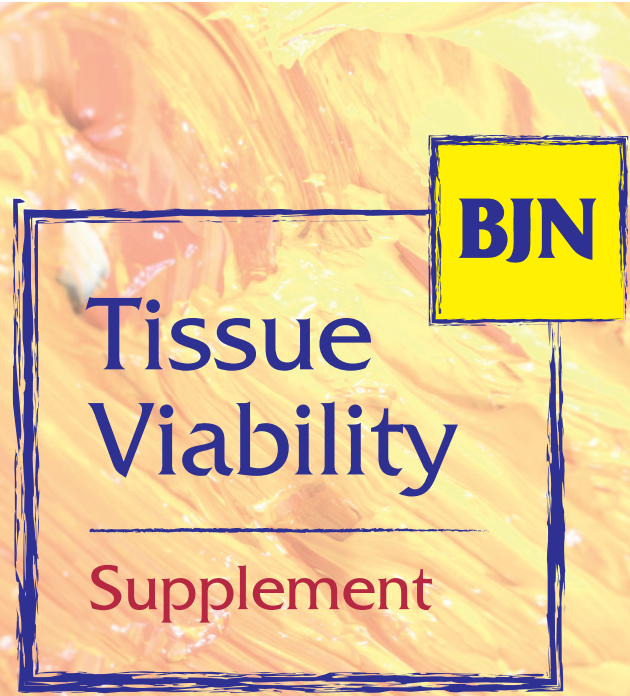

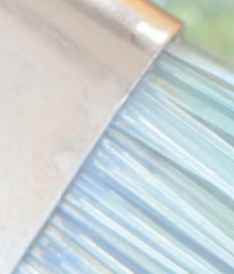

The British Journal of Nursing (BJN) Tissue Viability Supp

based practice and the provision of high quality patien articles including literature reviews, care studies and origina viability nursing. To contribute to the supplement or to enqu

peer reviewer in this area, contact us at bjn@markallengroup.com or 02075016702. 